\title{
Current and Future Directions of Research into Prematurity: Report of the Symposium on Prematurity Held on 21-22 November 2005
}

\author{
RICHARD P. LEAVITT, NANCY S. GREEN, AND MICHAEL KATZ \\ March of Dimes Birth Defects Foundation, White Plains, New York 10605
}

$\mathrm{T}$ he incidence of preterm birth (PTB) has risen steadily during the past $25 \mathrm{y}$, and now affects $12.5 \%$ of newborns in the United States, approximately half a million infants annually. It is the leading cause of neonatal complications and mortality, and early PTB ( $<32$ wk gestation) accounts for roughly half of all long-term neurologic morbidity in childhood (1).

The March of Dimes convened a symposium in November 2005 with the goal of bringing fresh perspectives to research on preventing prematurity. Participants included investigators who presented current understanding of origins of prematurity, other experts on human and nonhuman mammalian reproduction-as well as other fields of biology — whose roles included suggesting new avenues of research, and scientists whose research is already taking new and promising directions.

\section{CURRENT UNDERSTANDING OF ORIGINS OF PREMATURITY}

Epidemiology. The conceptualization of prematurity is shifting from simply a problem of late pregnancy to a common, complex chronic disease with origins early in pregnancy, or even preceding it. Genetic and environmental influences on common chronic diseases have conventionally been characterized simply, splitting causal pathways between genes and environment. However, genes and environment do not act separately. Almost all diseases are caused by geneenvironment interactions. Genetic factors that influence prematurity include certain known single gene disorders and as yet unidentified loci whose existence is inferred from familial aggregation of PTB.

Studies have found substantial heritability of prematurity. Although these studies show that genetic factors play a role, they do not specify how. A 1997 study found increased risk of preterm delivery that correlates with maternal gestational age at birth (2). A study of white and African American women found that $28 \%$ of white women who had a first delivery at 20-31 wk delivered their second child at 36 wk or less, and in African Americans that figure was 37\% (3). Research has begun to explore gene-environment interactions. For example, it has been found that maternal genotypes for two metabolizing

Received June 20, 2006; accepted August 24, 2006.

Correspondence: Richard P Leavitt, March of Dimes Birth Defects Foundation, 1275 Mamaroneck Avenue, White Plains, NY 10605 USA; e-mail: rleavitt@marchofdimes.com

DOI: 10.1203/01.pdr.0000246204.81584.23 enzymes modified the inverse association between maternal cigarette smoking and infant birth weight (4). Another study found that, among women who carry a variant of TNF-alpha known to be associated with preterm delivery, those with BV have a 6-fold increase in preterm birth, versus a 1.7-fold increase in those who are BV negative (5).

A global collaboration of individuals and organizations from 40 countries, the Human Genome Epidemiology Network, hopes to enhance the design and execution of epidemiologicgenetic association studies, conduct systematic reviews to establish a knowledge base to inform future studies, guide the research agenda, and inform health services and public policy. A HuGENet database has documented that epidemiologists have been steadily publishing more than 18,000 articles on the epidemiology of genes and have conducted more than 300 meta-analyses on specific gene-disease associations since 2001. Centers for Disease Control and Prevention has catalogued these articles into a database that is searchable by gene, disease, interacting risk factors, or other topics, accessible at http://www.cdc.gov/genomics/hugenet/. Using genomics in prematurity research can enable public health messages to be targeted, prevention strategies to be personalized, individuals and families at high risk to be identified, and applications of promising clinical treatments such as progesterone to be refined.

Genetics. Studies of twins have shown heritability. One involved 866 Swedish monozygotic twins and 1141 dizygotic twins delivered between 1973 and 1999 and later having their own offspring. The concordance rate was twice as high in monozygotic as in dizygotic twins (6). Another study looked at risk of preterm delivery in Utah between 1970 and 1992 in women who had been born at term or preterm between 1947 and 1957. The odds ratio for preterm delivery was 1.18 for women born preterm and 2.38 for those born at less than $30 \mathrm{wk}$ (7). Candidate genes for prematurity have generally fallen into four functional groups: 1) neurohormonal agents, such as those involved in ACTH production and activity; 2) inflammatory cytokines such as interleukins, tumor necrosis factor (TNF)- $\alpha$, heat shock proteins, and toll-like receptors; 3) decidualplacental vascular factors such as vascular endothelial growth

Abbreviations: BV, bacterial vaginosis; PPROM, preterm premature rupture of membranes 
factor, methyltetrahydrofolate reductase, paraoxonase, and epoxide hydrolase; and 4) myometrial factors, such as matrix metalloproteinases and estrogen receptors. However, candidate gene association studies have shown inconsistent findings and relatively small differences. Few studies have included more than a single ethnic group.

The premature population needs to be more effectively stratified. The focus should be on infants of gestational age 32 or 28 wk or less. We should conduct genome-wide analyses with well-defined criteria, excluding confounders such as preeclampsia. Studies should include focus on exceptional familial aggregates. Single nucleotide polymorphisms that are densely present throughout the genome should be analyzed, as well as heritability of expression in microarrays.

The future is not likely to be one of simple genome-wide analysis, but one involving a combined approach, such as whole genome analysis and the candidate gene approach. Alternatively, whole genome-wide analysis could be conducted that identifies those linked genes and, at the same time, combines the analysis with gene expression studies. Different genes will be found to cause very preterm birth and near-term birth. Those involving very preterm birth may prove to be the most important. The number of pivotal genes involved need not be overwhelming, and identifiable gene products and therapies can be envisioned.

Biochemical markers. Four main pathways lead to prematurity. They share a final common pathway but have different initiating biochemical sequences. They are 1) stress or premature activation of the fetal hypothalamic-pituitary-adrenal axis; 2) infection and/or exaggerated inflammatory response; 3) decidual hemorrhage/abruption; and 4) uterine overdistension due to multifetal gestation (8).

The link between stress and prematurity is the best defined. Women who have major life events during their pregnancy or are very anxious and depressed have a 2 -fold higher rate of prematurity (9). The fetus also can be stressed: between 25 and $50 \%$ of the placentas of women who deliver spontaneously preterm show evidence of vasculopathy, ischemia, failure of trophoblast invasion, and remodeling of the uteroplacental vascular circuit, and this can be accompanied by fetal growth restriction (10-12). Progressive uteroplacental insufficiency that activates the fetal hypothalamic-pituitary-adrenal axis leads to the increased production of ACTH and adrenal cortisol production. The latter induces placental production corticotropin releasing hormone, which then creates a feedforward loop of more ACTH production. Because corticotropin releasing hormone and cortisol enhance placental and fetal membrane cyclooxygenase activity, respectively, the net effect is increased prostaglandin production, which drives preterm delivery. Stress-induced preterm deliveries rarely occur before $28 \mathrm{wk}$.

The inflammatory pathway is predominantly a maternalinitiated pathway designed to facilitate delivery and ensure maternal survival in the face of potential sepsis. BV involves alteration of the vaginal flora that predisposes to overgrowth of facultative bacteria, and is twice as common in women who will deliver prematurely (13). Overgrowth of Gram-negative bacteria causes release of endotoxins that can induce the production of TNF and IL-1 $\beta$ locally (14), which stimulate expression of matrix metalloproteinases and cyclooxygenase. Genetic polymorphisms in immune response genes and/or their promoters (e.g. toll-like receptors, TNF, IL-1 $\beta$ ) have been linked to exaggerated immune response in women at risk for prematurity $(15,16)$.

The third pathway is placental abruption or hemorrhage into the wall of the uterus (i.e. decidua). Vaginal bleeding in just the first trimester doubles the risk of prematurity, and vaginal bleeding in more than one trimester leads to about a 50\% rate of PPROM. Abruption leads to prematurity through the generation of thrombin in excess quantities. Thrombin binds to protease activated receptors in the decidua and fetal membranes to cause release of matrix metalloproteinases and prostaglandins. Another feature of abruption-associated PPROM is decidual neutrophil infiltration, which results from the dramatic up-regulation of decidual IL-8 production by thrombin. It also has been shown that thrombin, in enough concentration in the myometrium, can bind to protease-activated receptors to directly induce contractions (17).

Finally, there is a dose response effect between the number of fetuses present in the uterus and gestational age at delivery. If the uterus distends more rapidly than it can grow, as occurs with multiple gestations, there is direct mechanical activation of the myometrium and release of cytokines from the fetal membranes, as well as increased production of prostaglandins in the cervix and myometrium (8). In addition, multifetal pregnancies with or without prior ovulation induction are associated with an increase in ovarian and decidual expression of the hormone relaxin, which can cause cervical shortening.

The four pathways have final common pathways of increased cyclooxygenase, matrix metalloproteinase, and IL-8 production, which leads to contractions and/or cervical change and PPROM. Ongoing research is directed at using these markers to predict the risk of preterm birth.

Role of the placenta. Major modulators of placental function are attachment, gas and nutrient transfer, hormone production, and immune modulation. Animal models have highlighted the importance of nutrition for placental function. Rats subjected to a substantial period of undernutrition gave birth to pups with a modest decrease in birth weight, a statistically significant increase in placental weight, and a decrease in the activity of a critical enzyme in the placenta that normally metabolizes maternal glucocorticoids to protect the fetus from their passage across the placenta into the fetal compartment (18). Ewes undernourished to an extent that reduced maternal body weight by $10-15 \%$ periconceptionally had markedly shortened average gestational lengths. Undernutrition resulted in precocious activation of pituitary adrenal function in about half of the fetuses, and in premature delivery (19).

Emerging data highlight the role of chorionic and placental enzymes, particularly prostaglandin dehydrogenase, which is progesterone-dependent as well as dependent on a local mechanism; thus, paracrine processes are involved, making it difficult to pick up systemic markers of changes. Another factor to consider is the placenta's immune regulatory role. The human placental membranes express antimicrobial molecules that are up-regulated in response to pro-inflammatory cyto- 
kines. Major research questions focus on understanding the regulation of these compounds and how they may affect inflammatory processes.

\section{RECOMMENDATIONS FOR NEW AVENUES OF RESEARCH}

Combine and expand human databases. It has become possible, although still challenging, to design studies of complex disorders involving multiple, interacting genetic and environmental factors. Before environmental and epidemiologic studies can be fully exploited, it will be important to understand contributing genotypes and their effects on phenotype to delineate the etiologies of preterm birth. The paucity of scientific knowledge concerning the basis of preterm birth, its heterogeneity, and complexity makes establishment of large, pooled specimen resources such as a national resource bank pivotal to progress in the field. The data sets from research funded by the March of Dimes on woman and their infants delivered preterm from various populations are extensive and can contribute to the identification of common and/or strong elements in etiology of preterm birth, especially if the data sets are astutely combined. Enriching and exploiting the data will require efforts across multiple disciplines, including psychology, nutrition, and immunology. Pooled data from these and other sources to establish a national biologic specimen bank may provide greater precision with less variability in ascertaining etiologies, and may differentiate phenotypes of preterm birth. Existing databases and repositories are likely to contain vast amounts of data to be mined, but many have not been thoroughly or systematically explored for genomic or phenotypic data.

In addition to pooling data from existing sources, there should be an effort to identify and collect data and samples from families in which there is strong family history of very early prematurity. These data can be placed in a repository with the consent of the subjects and made available to bona fide researchers to conduct anything from a genome-wide scan to a candidate gene analysis. Prenatal care should be the starting place for regularly banking specimens. Groups such as the March of Dimes, the American College of Obstetricians and Gynecologists, and the American Academy of Pediatrics could play pivotal roles in encouraging relevant research, in identifying candidate families for such repositories, and in educating the public and professional communities about the need for such resources in conducting research on preterm birth. A major challenge with organizing such a database is its cost and consequently its sustainability.

Apply new methods to reassess old findings. Many questions about origins of prematurity have been studied with equivocal and conflicting results. Some important studies were carried out in a more distant past and now deserve reexamination as modern methods evolve. For example, BV is clearly linked to preterm delivery, but treating it with antibiotics has not prevented prematurity in most groups of women studied. A possible reason is that $\mathrm{BV}$ has been clinically defined, but is largely undefined in terms of the many and highly diverse microorganisms involved. We know now that there are mi- croorganisms that do not grow in the ordinary media and cannot be isolated by the traditional bacteriological methods. Use of indirect methods, such as the PCR, for example, may reveal correlations heretofore not established. Almost nothing is known about individual differences that may make some women susceptible to the effects of $\mathrm{BV}$ and make them react in ways that lead to preterm delivery. Using molecular genetic analysis of vaginal flora in $\mathrm{BV}$ could be one way to shed light on the role of BV.

Similarly, nutritional studies that have generally failed to show effects on timing of delivery might be revisited by analysis of micronutrients rather than just caloric intake. Also, in clinical studies of ways to predict or prevent preterm birth, new methods may help to stratify subjects into more homogeneous comparison groups than has been possible in the past.

Expand use of animal models. Animal models, especially transgenic and knockout mice, can provide insights that are unattainable in human studies. Study of preterm birth in animals, including mice and livestock, can help ascertain potential nutritional and environmental factors. Comparative studies across species may illuminate the biologic processes in humans.

Explore new candidate genes. Candidate gene studies will need to be combined with genome-wide analyses, with special attention to evolutionarily conserved genomic elements. Extreme phenotypes are likeliest to be most informative. Research on preterm birth should take advantage of contemporary insights into the molecular basis for regulating gestation and parturition. Many biologic processes are governed by oscillating or "clock" genes, ranging from diurnal rhythms and menstrual cycles to skeletal growth and aging. Such genes should be among prime candidates for identification and study as timers of gestation. Animal models may be especially useful in this avenue of investigation, and some such studies are now underway.

\section{Participants}

Duane Alexander, Director, National Institute of Child Health and Human Development; Gary Althouse, Associate Professor, Clinical Studies, University of Pennsylvania School of Veterinary Medicine; Diane Ashton, Associate Medical Director, March of Dimes; Carol Baker, Professor, PediatricsInfectious Diseases, Baylor College of Medicine; Richard Behrman, Executive Chair, Federation of Pediatric Organizations; Colleen Boyle, Director, Division of Birth Defects and Developmental Disabilities, Centers for Disease Control and Prevention; John Challis, Vice-President, Research and Assistant Provost, Professor of Physiology and of Obstetrics and Gynecology, University of Toronto; Harvey J. Cohen, Professor and Chair of Pediatrics, Stanford University; Karla Damus, Senior Research Associate and Epidemiologist, March of Dimes; Siobhan M. Dolan, Consultant, Office of the Medical Director, March of Dimes; Frederic Frigoletto, Professor, Obstetrics and Gynecology, Harvard Medical School; Ronald S. Gibbs, Professor and Chair, Obstetrics and Gynecology, University of Colorado; Jonathan Gitlin, Helene B. Roberson Professor of Pediatrics, Washington University; Laura Gold- 
smith, Professor, Obstetrics, Gynecology and Women's Health, New Jersey Medical School; Michael F. Greene, Professor of Obstetrics, Gynecology and Reproductive Biology, Harvard Medical School; Kurt Hirschhorn, Professor of Pediatrics, Human Genetics and Medicine, Mount Sinai School of Medicine; Calvin J. Hobel, Professor and Vice Chair, Obstetrics and Gynecology, Cedars-Sinai Medical Center; Claudia Holzman, Associate Professor, Department of Epidemiology, Michigan State University; Richard B. Johnston, Jr., Professor of Pediatrics, University of Colorado; John Kessler, Professor and Chair, Davee Department of Neurology and Clinical Neurologic Sciences, Northwestern University Medical School; Muin J. Khoury, Director, Office of Genomics and Disease Prevention, Centers for Disease Control and Prevention; Story Landis, Director, National Institute of Neurologic Disorders and Stroke; Charles J. Lockwood, Professor and Chair, Department of Obstetrics, Gynecology and Reproductive Sciences, Yale University School of Medicine; Lynn Loriaux, Professor and Chairman of Medicine, Oregon Health Sciences University; Stephen J. Lye, Vice-President, Research, and Associate Director, Samuel Lunenfeld Research Institute, Mount Sinai Hospital, Professor, Departments of Obstetrics and Gynecology and of Physiology, University of Toronto; Mala Mahendroo, Assistant Professor, Department of Obstetrics and Gynecology, University of Texas Southwestern Medical Center; Carole R. Mendelson, Professor, Departments of Biochemistry and Obstetrics and Gynecology, University of Texas Southwestern Medical Center; Louis J. Muglia, Associate Professor, Departments of Pediatrics, Molecular Biology, Pharmacology, and Obstetrics and Gynecology, Washington University; Michael Nelson, Virginia S. Lang Professor and Vice Chairman, Obstetrics and Gynecology, Washington University School of Medicine; Robert Nussbaum, Chief, Genetic Diseases Research Branch, National Human Genome Research Institute; Nigel Paneth, Associate Dean for Research, Professor of Epidemiology and Pediatrics, Michigan State University; Joe Leigh Simpson, Professor and Chair, Obstetrics and Gynecology, Professor, Molecular and Human Genetics, Baylor College of Medicine; Catherine Spong, Branch Chief, National Institute of Child Health and Human Development; Jerome F. Strauss, III, Dean, School of Medicine, Virginia Commonwealth University and Executive Vice President for Medical Affairs, VCU Health System; Xiaobin Wang, Associate Pro- fessor and Chair, Department of Pediatrics, The Smith Child Health Research Program, Children's Memorial Hospital; Jeffrey Whitsett, Professor of Pediatrics, University of Cincinnati College of Medicine; Christopher Wilson, Professor and Chair of Immunology, University of Washington; Roy Woychik, Director, The Jackson Laboratory.

\section{REFERENCES}

1. Goldenberg RL 2002 The management of preterm labor. Obstet Gynecol 100:1020 1037

2. Porter TF, Fraser AM, Hunter CY, Ward RH, Varner MW 1997 The risk of preterm birth across generations. Obstet Gynecol 90:63-67

3. Adams MM, Elam-Evans LD, Wilson HG, Gilbertz DA 2000 Rates of and factors associated with recurrence of preterm delivery. JAMA 283:1591-1596

4. Wang X, Zuckerman B, Pearson C, Kaufman G, Chen C, Wang G, Niu T, Wise PH, Bauchner H, Xu X 2002 Maternal cigarette smoking, metabolic gene polymorphism, and infant birth weight. JAMA 287:195-202

5. Macones GA, Parry S, Elkousy M, Clothier B, Ural SH, Strauss JF 3rd 2004 A polymorphism in the promoter region of TNF and bacterial vaginosis: preliminary evidence of gene-environment interaction in the etiology of spontaneous preterm birth. Am J Obstet Gynecol 190:1504-1508

6. Clausson B, Lichtenstein P, Cnattingius S 2000 Genetic influence on birthweight and gestational length determined by studies in offspring of twins. BJOG 107:375-381

7. Porter TF, Fraser AM, Hunter CY, Ward RH, Varner MW 1997 The risk of preterm birth across generations. Obstet Gynecol 90:63-67

8. Lockwood CJ 2002 Predicting premature delivery-no easy task. N Engl J Med 346:282-284

9. Dole N, Savitz DA, Hertz-Picciotto I, Siega-Riz AM, McMahon MJ, Buekens P 2003 Maternal stress and preterm birth. Am J Epidemiol 157:14-24

10. Arias F, Rodriguez L, Rayne SC, Kraus FT 1993 Maternal placental vasculopathy and infection: two distinct subgroups among patients with preterm labor and preterm ruptured membranes. Am J Obstet Gynecol 168:585-591

11. Salafia CM, Ghidini A, Lopez-Zeno JA, Pezzullo JC 1998 Uteroplacental pathology and maternal arterial mean blood pressure in spontaneous prematurity. J Soc Gynecol Investig 5:68-71

12. Germain AM, Carvajal J, Sanchez M, Valenzuela GJ, Tsunekawa H, Chuaqui B 1999 Preterm labor: placental pathology and clinical correlation. Obstet Gynecol 94:284-289

13. Meis PJ, Goldenberg RL, Mercer B, Moawad A, Das A, McNellis D, Johnson F, Iams JD, Thom E, Andrews WW 1995 The preterm prediction study: significance of vaginal infections. National Institute of Child Health and Human Development Maternal-Fetal Medicine Units Network. Am J Obstet Gynecol 173:1231-1235

14. Kim YM, Romero R, Chaiworapongsa T, Kim GJ, Kim MR, Kuivaniemi H, Tromp G, Espinoza J, Bujold E, Abrahams V, Mor G 2004 Toll-like receptor-2 and -4 in the chorioamniotic membranes in spontaneous labor at term and in preterm parturition that are associated with chorioamnionitis. Am J Obstet Gynecol 191:1346-1355

15. Roberts AK, Monzon-Bordonaba F, Van Deerlin PG, Holder J, Macones GA, Morgan MA, Strauss JF, Parr S 1999 Association of polymorphism within the promoter of the tumor necrosis factor $\alpha$ gene with increased risk of preterm rupture of the fetal membranes. Am J Obstet Gynecol 180:1297-1302

16. Fujimoto T, Parry S, Urbanek M, Sammel M, Macones G, Kuivaniemi H, Romero R, Strauss JF 2002 A single nucleotide polymorphism in the matrix metalloproteinase-1 (MMP-1) promoter influences amnion cell MMP-1 expression and risk for preterm premature rupture of the fetal membranes. J Biol Chem 277:6296-6302.

17. Elovitz MA, Saunders T, Ascher-Landsberg J, Phillippe M 2000 Effects of thrombin on myometrial contractions in vitro and in vivo. Am J Obstet Gynecol 183:799-804

18. Langley-Evans SC, Phillips GJ, Benediktsson R, Gardner DS, Edwards CR, Jackson AA, Seckl JR 1996 Protein intake in pregnancy, placental glucocorticoid metabolism and the programming of hypertension in the rat. Placenta 17:169-172

19. Bloomfield FH, Oliver MH, Hawkins P, Campbell M, Phillips DJ, Gluckman PD, Challis JR, Harding JE 2003 A periconceptional nutritional origin for noninfectious preterm birth. Science 300:606 